\title{
Nucleation modeling of the Antarctic stratospheric CN layer and derivation of sulfuric acid profiles
}

\section{Steffen Münch and Joachim Curtius}

Correspondence to: Steffen Münch (steffen.muench@env.ethz.ch)

The copyright of individual parts of the supplement might differ from the CC BY 3.0 License. 


\section{S1 Additional sensitivity studies}
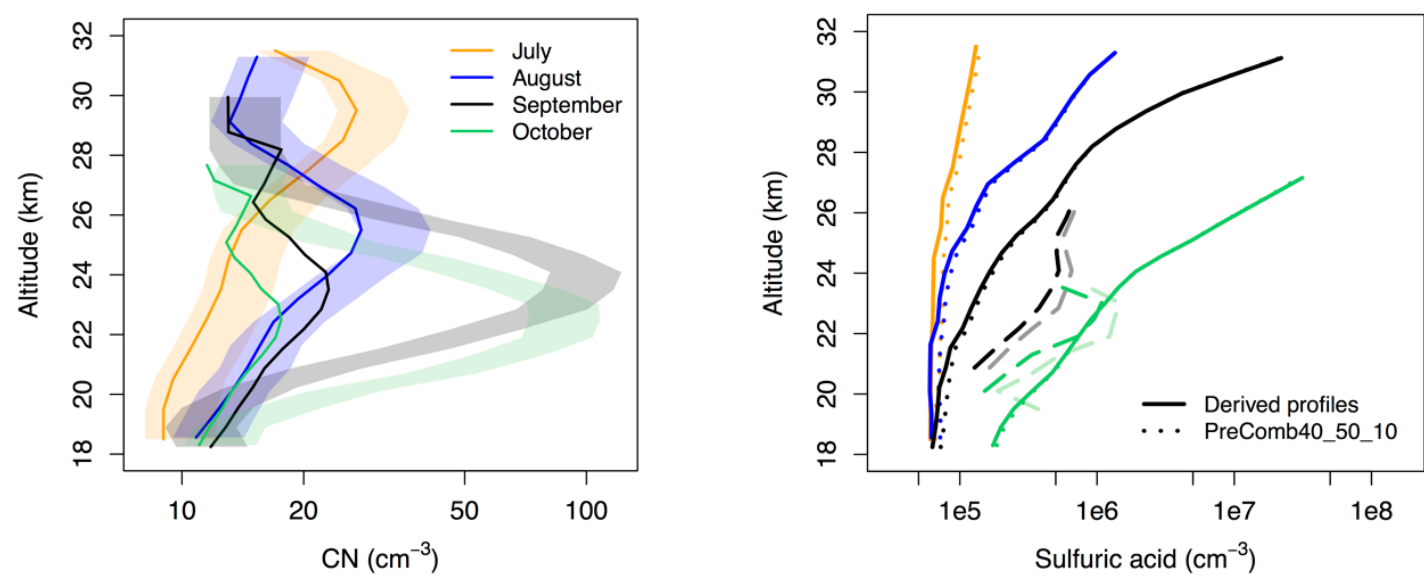

Figure S1: Preexisting particles: $10 \%$ are $300 \mathrm{~nm}, \mathbf{5 0 \%}$ are $100 \mathrm{~nm}$, and $40 \%$ are $50 \mathrm{~nm}$ in size (as Fig. 2b and Fig. 4)
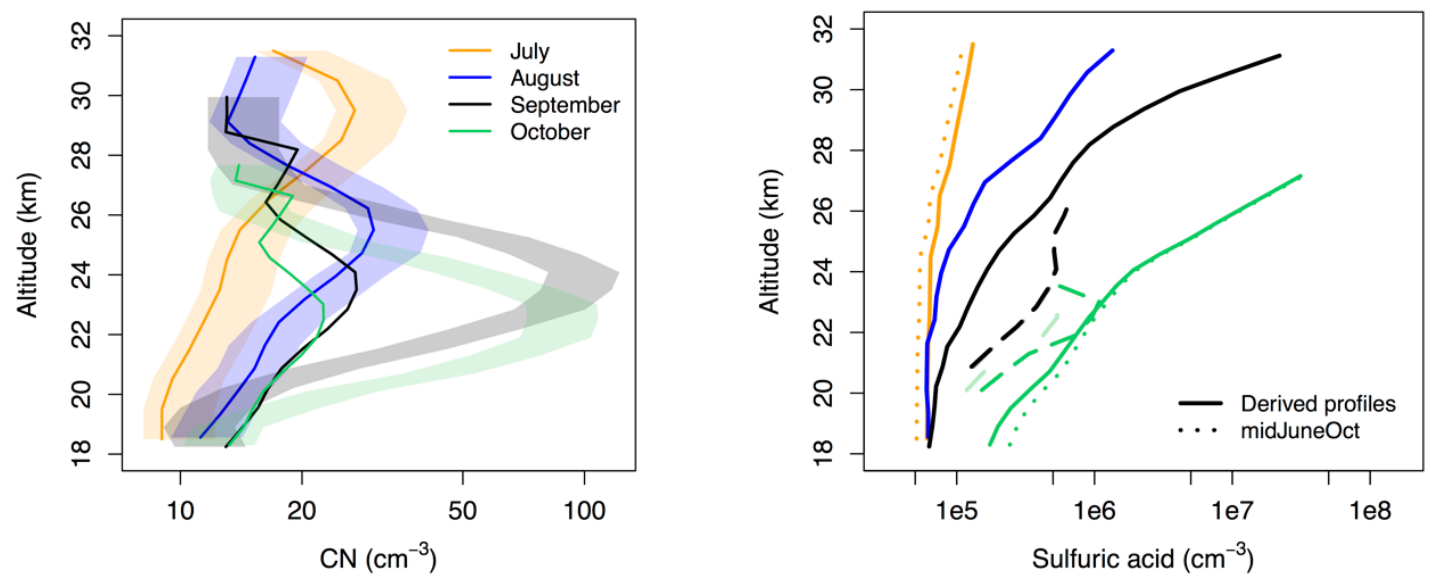

Figure S2: Run simulation from mid June until mid October. August and September profiles do not change (as Fig. $2 \mathrm{~b}$ and Fig. 4)
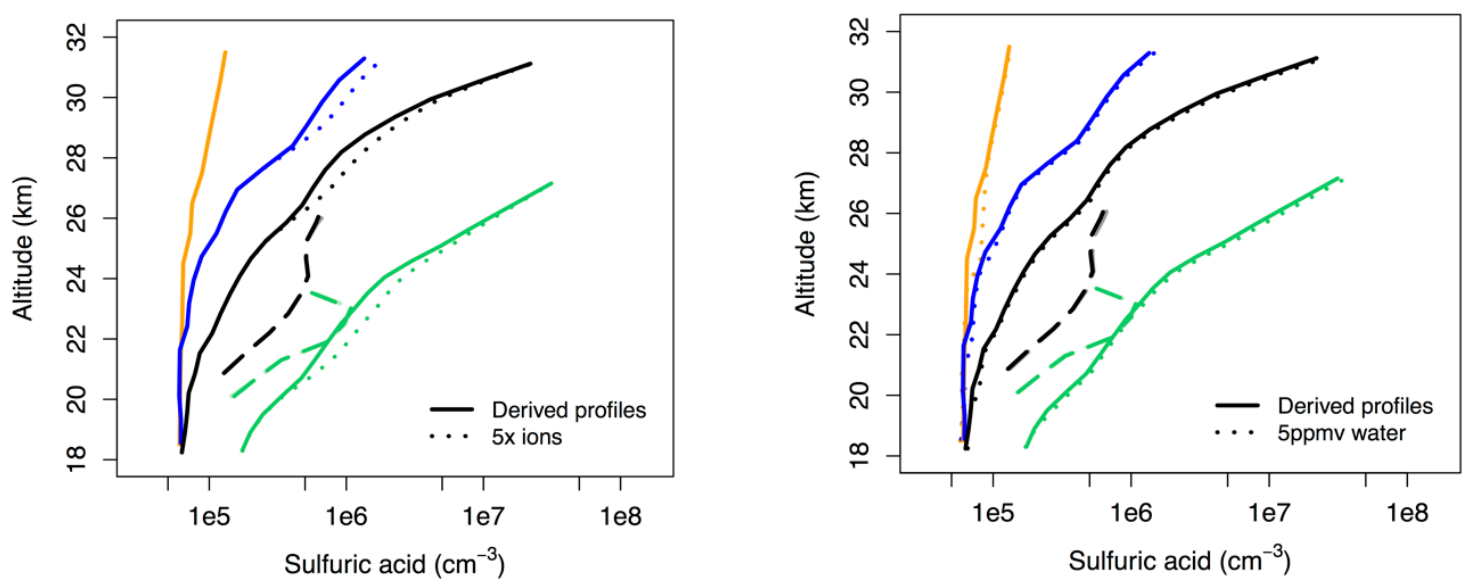

Figure S3: $5 x$ ion production rates everywhere (left) and 5 ppm water vapor everywhere (right) (as Fig. 4) 


\section{S2 Estimation of the trajectories}

For the July altitudes we start at $18.5 \mathrm{~km}$ and then go up in steps of $1 \mathrm{~km}$. For the following months the values are determined by using the following estimates:

$$
\begin{gathered}
\text { August }=\text { July }-4.0 \cdot \frac{J u l y-X}{29.0-X} \\
\text { September }=\text { August }-2.0 \cdot \frac{\text { August }-X}{25.5-X} \\
\text { October }=\text { September }-1.0 \cdot \frac{\text { September }-X}{23.5-X}
\end{gathered}
$$

with $\mathrm{X}=15$ above the $\mathrm{CN}$ maximum trajectory and $\mathrm{X}=12$ below it.

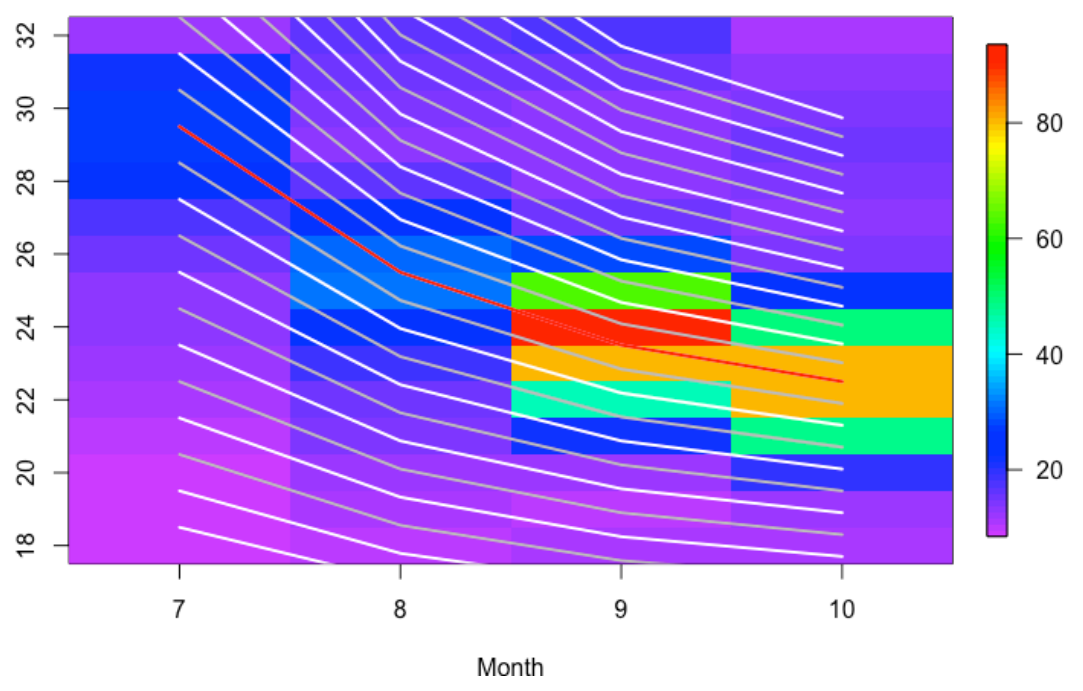

Figure S4: Trajectories plotted over the measured CN concentrations from Campbell and Deshler (2014) (in color, cm-3) 